\title{
IMPLICAÇÃO, SOBREIMPLICAÇÃO E IMPLICAÇÃO PROFISSIONAL ${ }^{\star}$
}

Gilles Monceau ${ }^{\star}$

\begin{abstract}
ReSUMO
O artigo busca discutir um dos conceitos básicos da Análise Institucional, a implicação. Para tanto, traz também outros conceitos que dela derivam el ou modulam: sobreimplicação e implicação profissional. Trazendo exemplos presentes em diferentes espaços, na escola, na universidade, no hospital analisa a tendência da "universitarização" das profissões, onde os profissionais são convocados a trabalhar suas dificuldades práticas pelo discurso, ao modo do fazer universitário, como se a análise discursiva da prática permitisse fazer evoluir a própria prática.
\end{abstract}

Palavras-chave: Implicação. Sobreimplicação. Análise institucional.

\section{IMPLICATION, OVER IMPLICATION AND PROFESSIONAL IMPLICATION}

\begin{abstract}
This article debates one of the basic concepts of Institutional Analysis: implication. For that purpose, brings two other concepts that stem from it: over implication and professional implication. Both rather important for the implications analyses process. Pointing out that implication analyses is a collective work, the text board the devices that those analyses can construct. Bringing examples of different spaces, in the school, in the university, in the hospital, it is analysed the tendency to give a universitarian form to the professions, when professionals are called to work their practical difficulties, doing it through the discourse, as used in the universities, as if the discursive analyses of the practice allowed the evolution of their practice.
\end{abstract}

Keywords: Implication. Over implication. Institutional analyses.

\footnotetext{
^ Tradução: Maria Lívia do Nascimento e Teresa Cristina Carreteiro

$\star \star$ Professor do Departamento de Ciências da Educação da Universidade de Paris 8 e coordenador do L'Axe socio-clinique institutionnel de l'équipe de recherche ESSI da mesma universidade. Adresse: 2 rue de la Liberte. 93526 Saint-Denis Cedex.

E-mail: Gilles.Monceau@univ-paris8.fr
} 
Para discutir esse tema, apresento algumas publicações ${ }^{1}$ referentes à questão da clínica institucional. Começo pela Revue d'Analyse Institutionnelle. Les Cahiers de l'Implication, número $1,{ }^{2}$ que reuniu artigos sobre o tema da auto-gestão. Para nós, na França, essa temática parecia algo bem antigo, um conceito muito ligado aos anos de 1960, 1970 e em particular a maio/68. Naquela época, particularmente nos anos de 1970, muitos grupos funcionavam sob o modelo da autogestão, tanto em empresas pequenas quanto nos estabelecimentos de educação.

A história da Análise Institucional está muito vinculada à história da autogestão. Em particular, nos textos dos anos de 1970 encontramos muitas referências a esse tema. A idéia era que o funcionamento de auto-gestão de certos grupos permitia analisar as instituições e seus modos de gerenciamento instituídos e burocratizados. Certos grupos, por exemplo, os grupos politizados, vão buscar alternativas, inventando outras formas de direção, não se submetendo àquelas vigentes, tendo como objetivo lutar contra as formas de alienação. Este objetivo fragmentou o mundo político.

Os militantes da auto-gestão tiveram e, ainda têm hoje, conflitos muito tensos com os marxistas, por exemplo. A própria Análise Institucional tem muitas dificuldades com os marxistas, com os comunistas. Existem muitas histórias em certos partidos e também dentro da universidade que giram em torno desses conflitos. Os marxistas, por muito tempo, acusaram as pessoas que trabalham com auto-gestão de impedir a revolução, porque elas inventam, localmente, formas alternativas de funcionamento, independente de uma revolução global.

Nós decidimos re-trabalhar o tema da auto-gestão, mesmo sendo ele considerado algo envelhecido, e trabalhando sobre esse tema, discutindo com alguns dos autores que nos propuseram seus artigos, percebemos que havia vida em torno da questão da auto-gestão. Podemos citar o exemplo ocorrido na Argentina com as empresas recuperadas pelos trabalhadores quando os proprietários foram embora.

No terreno da educação existem, ainda hoje, estabelecimentos que funcionam de forma auto-gestiva. Da mesma forma, existem práticas de pesquisa, que eu chamo de sócio-clínicas, que seguindo a Análise Institucional, propõem que para analisar as instituições é preciso provocar certa ruptura no funcionamento instituído. Por exemplo, quando fazemos intervenções em estabelecimentos de educação ou médico-sociais, ficamos atentos para não reproduzir na intervenção o mesmo tipo de funcionamento do cotidiano. Habitualmente, iniciamos as intervenções fazendo assembléias gerais nas quais todas as pessoas do estabelecimento se encontram presentes, tanto a cozinheira quanto o psiquiatra. Nessas assembléias falamos tanto da encomenda feita pelo diretor geral, por exemplo, quanto do dinheiro que foi investido para que o trabalho fosse realizado. Evidentemente essa maneira de intervir transforma a relação de saber e de poder desse estabelecimento. Existe aí um interesse de trabalho auto-gestivo que permite produzir análises novas, mesmo se essa auto-gestão se limita ao trabalho da intervenção. Assim é que essa temática da auto-gestão deu ensejo a esse número da revista. 
Outra publicação que gostaria de citar é a L'Homme et la Société (2003), revista na qual René Lourau publicou muitas vezes. No número especial que coordenei com Antoine Savoye, já a partir do título tentamos cruzar uma perspectiva sócio-clínica com uma perspectiva sócio-histórica. Essa dupla orientação sempre esteve presente na Análise Institucional desde o seu início, pois se fazemos intervenções em situações aqui e agora, temos necessidade de fazer uma análise da institucionalização desse aqui e desse agora. Não podemos produzir um trabalho de análise local se não a situamos na transformação institucional à qual pertence essa situação local. Essa dupla orientação, sócio-clínica e sócio-histórica, reúne o conjunto dos nossos trabalhos.

No livro Instituition et Implication. L'oeuvre de René Lourau (LAMIHI; MONCEAU, 2002) encontramos 17 artigos escritos por pesquisadores franceses. Cada um deles se dedica a uma obra de René Lourau, através de dois conceitos principais: instituição e implicação. Apesar do livro mais conhecido desse autor ser "L'analyse institutionnelle", uma grande parte de seus trabalhos foi dedicada ao conceito de implicação.

René Lourau começou a trabalhar essa questão da implicação, junto com Lapassade, nas situações de intervenção que eles passaram a chamar de sócioanálise. Dentre as diferentes operações socioanalíticas imaginadas por Lourau e Lapassade, o momento da análise das implicações, tanto das pessoas que coordenavam, quanto daquelas que participavam, era muito marcante e essencial. Ou seja, a análise de implicações dos coordenadores da intervenção, sociólogo, psicólogo ou psicossociólogo, era um momento crucial, sobretudo porque naquela época não era comum considerar a implicação dos analistas na situação de análise.

O conceito de implicação foi por eles trabalhado em discussão, e também em oposição, com o conceito de transferência e contra-transferência da psicanálise. Consideravam que a separação entre transferência e contra-transferência não tinha nenhum sentido, pois os analistas, como os analisandos, têm a mesma natureza. $\mathrm{O}$ que os distingue é a posição do dispositivo de análise e em particular a relação de saber e a relação de poder. Foi provocando uma análise de implicação que a Análise Institucional tentou fazer uma análise da instituição. É nesse sentido que entendo o conceito de implicação. Esta precisão é muito importante, porque existem muitos mal-entendidos em torno desse conceito, tanto na Europa como na América do Sul. Sempre encontro o mesmo tipo de mal-entendido quando discuto esse conceito.

O que entendo por implicação é a relação que indivíduos desenvolvem com a instituição. Nós podemos dizer que o indivíduo é tomado pela instituição, querendo ele ou não. Eu não tenho a possibilidade de decidir que não estou implicado na instituição universitária francesa, mesmo que eu possa ter posições bastante críticas, mesmo que eu queira tomar uma distância, eu sou tomado por essa instituição. Lourau tinha uma frase que eu guardo de memória porque ilustra bem essa idéia. Ele dizia: "A instituição fala pelo ventre, falando por nossa boca". É uma imagem que vem contradizer certas definições de implicação. Não podemos confundir implicação com engajamento, com investimento. 
De maneira mais ampla, numa democracia, o cidadão que não vota está tão implicado como aquele que vota. Podemos dizer que aquele que não vota deixa que os outros o façam por ele. Se quisermos falar em termo de culpa ou de responsabilidade, tanto um quanto o outro são igualmente responsáveis pelo voto. Então, podemos dizer que a implicação existe mesmo que não a desejemos. Trata-se, pois, de analisar mais o modo de implicação do que sua existência, ou a quantidade de implicação, já que ela não pode ser medida em peso. Entretanto, podemos distinguir implicações econômicas, ideológicas, organizacionais, materiais, ou libidinais. Trata-se de compreender nossa modalidade de relação com a instituição porque essa implicação tem efeitos mesmo que nós não saibamos.

A análise de implicação é necessariamente um trabalho coletivo. Eu não posso analisar minhas implicações sozinho em meu canto. Os dispositivos de análise que construímos são, pois, sempre coletivos e geralmente temos vários analistas em cada intervenção. Sempre presente no trabalho de análise, podemos distinguir dois tipos de implicações, primárias e secundárias. Para simplificar, podemos dizer que nossas implicações primárias são nossas implicações dentro da própria situação de intervenção e as implicações secundárias são nossas implicações do campo de análise. Por exemplo, quando eu faço uma intervenção, um trabalho sócio-clínico em uma equipe de educação, minhas implicações primárias vão ter um lugar aqui e agora na situação de análise, nas relações que eu construí com aqueles que solicitaram a intervenção. As implicações secundárias podem estar em outro lugar, por exemplo, na instituição universitária. Posso dizer, principalmente na instituição universitária, pois quando eu faço uma intervenção junto a uma equipe, eu já pensei em como vou poder fazer publicações na esfera universitária. Esses elementos institucionais escapam totalmente aos meus interlocutores locais. Entretanto, essas implicações secundárias determinam, em grande parte, o que eu vou fazer no real, no campo de intervenção.

Dessa forma, essa primeira abordagem da questão da implicação na situação de intervenção deu, permitiu uma segunda perspectiva de intervenção, questão muito importante, que são as implicações dos pesquisadores na própria pesquisa.

Dois livros de Lourau discutem esse tema: Le journal de recherche (1988) e Actes manqués de la recherche (1994). A idéia é que o trabalho do pesquisador está saturado de subjetividade. As instituições científicas vão ter as suas próprias ideologias. Elas não são particularmente objetivas, mesmo se elas tentam nos fazer acreditar nisso. Esta questão da implicação do pesquisador foi muito trabalhada na pesquisa em sociologia, na pesquisa psicossociológica, mas podemos perguntar quais são as conseqüências da implicação do pesquisador na sua produção científica. A questão não é que devamos nos livrar de nossas ideologias, mas tentar analisá-las coletivamente. O verdadeiro trabalho científico deve estar aí.

Gostaria de citar aqui o trabalho da etinóloga Jeanne Favret-Saada (1981), publicado na França nos anos 1980. Ela fez uma pesquisa sobre a bruxaria na região de Bocage, na Normandia. Em seu diário de campo descrevia precisamente as relações que construía com os habitantes daquela região. Um momento decisivo para sua pesquisa, para compreender o mecanismo da bruxaria foi quando 
as pessoas lhe perguntaram se ela poderia tirar a bruxaria deles. Quer dizer, as pessoas com quem ela desenvolvia a pesquisa lhe deram um lugar no sistema de bruxaria. A partir desse momento, ela pôde produzir novos resultados de pesquisa, radicalmente diferente de todos os trabalhos anteriores nos quais os etimólogos interrogavam as pessoas que estavam tomadas pela bruxaria, tentando estar o mais distanciado possível.

Existem outros exemplos desse tipo e eu vou lhes dar o nome de um outro autor. O trabalho de George Devereux (1967), particularmente, seu livro Da angústia ao método, no qual defende a idéia que a metodologia de pesquisa é, sobretudo, criada pelo pesquisador para que ele possa se proteger de perturbações e de angústias pessoais que outras culturas, outras práticas podem provocar no pesquisador. Para Devereux não devemos tentar fazer desaparecer essa perturbação, ela deve ser analisada, pois é sua análise que trará um conhecimento novo.

Esses pesquisadores não se interessavam pela Análise institucional mas a Análise Institucional se interessou muito por eles, em particular pela questão da implicação. Sobre o tema, alguns artigos são importantes. Um primeiro, intitulado "Enquête sur les monographies d'interventions socianalytiques (1962-1999)" (MONCEAU, 2001), é resultado de uma enquete feita a partir de 50 intervenções que utilizaram a Análise Institucional, entre 1962 e 1999. O que me interessa nesse trabalho arqueológico é saber de que maneira as regras da sócioanálise, e particularmente a questão da análise de implicações, são mais ou menos respeitadas no conjunto dessas intervenções. Um outro, é o artigo "Transformar as práticas para conhecê-las: pesquisa-ação e profissionalização docente" (MONCEAU, 2005), sobre a pesquisa-ação, o trabalho sócio-clínico com professores, onde trato, sobretudo, da implicação.

O conceito de sobreimplicação, que permite uma melhor compreensão do conceito de implicação, poderia ser definido como uma impossibilidade de analisar a implicação. Posso dar um exemplo, que não gosto muito e, na França, os pesquisadores em educação também não gostam, que é a sobreimplicação dos pesquisadores na instituição escolar. Acredito que na França a maior parte dos trabalhos em sociologia e educação são trabalhos sobre a sobreimplicação. Os sociólogos da educação são muito vinculados à instituição escolar. Por exemplo, eles são os primeiros a fazer abaixo-assinados quando a escola é ameaçada. Este elemento pode ser politicamente simpático, eu faço a mesma coisa, mas por outro lado, essa sobreimplicação escolar nos impede de ver outras coisas. Por exemplo, quando eu trabalho com certos profissionais de educação, com dispositivos de educação para jovens que recusam a escola, creio que posso dizer que sou muito influenciado pelo fato de pessoalmente achar que a escola é importe para o desenvolvimento pessoal e político dos indivíduos.

O fato de o pesquisador achar que a escola é desejável, torna seu trabalho de análise particularmente complicado. Para nós, a instituição escolar não é um objeto frio. Tenho uma dificuldade muito grande de imaginar que um jovem possa estar em outro lugar que não na escola. É claro que esse fenômeno vai ser a conjunção de várias histórias, eu mesmo fui professor primário, me formei em peda- 
gogia, eu formei e formo ainda professores e formadores de professores e é claro que eu acho o trabalho deles muito importante e politicamente essencial. Por outro lado, existe a história da república francesa. Para nós a igualdade entre os cidadãos passa pela escola. Não há igualdade política sem que haja escolarização.

Eu poderia também encontrar outras razões, mas quando trabalho com uma equipe de educação sobre a desescolarização, é importante que trabalhemos nossas implicações na instituição escola, porque se não, naturalizaremos o fenômeno da escolarização. A escolarização é uma produção institucional, não é um presente divino nem um fenômeno natural. Para que possamos fazer uma pesquisa minimamente séria sobre a desescolarização, nós devemos trabalhar essa implicação. Os professores e os educadores que trabalham com jovens desescolarizados devem trabalhar essa implicação, que para eles é a implicação profissional. Eles vão trabalhar com os alunos, pensando que estão realizando também um trabalho político. Quando um aluno recusa a escola, para um professor comum é algo absolutamente inaceitável. Um professor que aceita a desescolarização vai aceitar, ao mesmo tempo, que esse aluno não será um cidadão como os outros. Em certo número de situações, essa sobreimplicação do profissional lhe conduz a aceitar práticas que ele também recusa. Por exemplo, um professor que recusa em teoria que a polícia intervenha na escola, poderá aceitar a vinda da polícia à escola sob a condição que ela permita que o aluno continue na escola. Isso vai produzir contradições institucionais muito fortes.

Finalizo a questão das implicações profissionais dizendo que atualmente assistimos, creio que no mundo inteiro, o fenômeno da profissionalização. Geralmente, esse fenômeno é visto como um simples fenômeno que diz respeito à formação. Entretanto, parece-me que cada vez mais ele é puramente político, uma maneira nova de gerir as profissões. De gerir tanto as profissões quanto os profissionais, dando-lhes a impressão de que são autônomos e responsáveis. O que eu chamo de profissionalização corresponde a vários elementos que não poderei desenvolver aqui, mas que se traduzem principalmente pela "universitarização" das profissões. Isto é, a formação profissional se desenvolve cada vez mais na universidade, seguindo a maneira de fazer da universidade.

Talvez o melhor exemplo da profissionalização seja a da medicina. Há muito tempo a medicina é uma formação universitária. A medicina tem uma prática médica e ao mesmo tempo um discurso sobre essa prática médica. Para se tornar um médico é preciso escrever uma tese em medicina. Na França, é a defesa oral da tese escrita que vai permitir ao aluno se tornar médico e não o controle de suas capacidades como clínico. Esse modelo se generaliza hoje nas profissões ligadas à saúde, à educação, à psicologia e até mesmo à polícia. Cada vez mais existem discursos sobre uma profissão, cada vez mais existem exigências escritas sobre as profissões. Assim, uma profissão vai atingir o seu reconhecimento quando encontra um lugar na universidade, quando consegue financiamentos para suas pesquisas, quando produz revistas científicas. Uma profissão, pois, deve ser capaz de explicitar sua prática, o que tem conseqüências no seu fazer cotidiano, em sua atuação mais banal. Quando, por exemplo, educadores ou enfermeiros trabalham no dia-a-dia, essa evolução da profissionalização causa certo distúrbio às práticas. 
Cada vez mais encontro, em meu trabalho sócio-clínico, profissionais perturbados. Freqüentemente eles dizem que são as crianças, os usuários, os doentes que os perturbam. Por exemplo, se queixam muito da violência das crianças, ou dos doentes, mas quando fazemos um trabalho sócio-clínico de longa duração com eles, quando levamos a sério suas queixas e suas ansiedades, vemos que esse mal-estar profissional vem da ocorrência desse processo de profissionalização. Alguns profissionais dizem que esse mal-estar aparece quando não encontram mais na profissão os valores que os impulsionaram a entrar nela. Por exemplo, os educadores dizem que escolheram ser educadores para trabalhar diretamente com as crianças, para desenvolver atividades, brincar com as crianças, ter relações próximas a elas. No campo da saúde, temos a mesma coisa, enfermeiras que se queixam da transformação técnica do trabalho que desenvolvem. Elas dizem que passam mais tempo escrevendo e administrando situações institucionais do que trabalhando diretamente com os doentes. Dizem que não têm mais tempo para escutar os doentes, prática que acreditam ser muito importante para o processo de cura. Acreditam que o aparato tecnológico e farmacêutico não é suficiente, e que a escuta do doente tem papel fundamental no seu processo de cura. O que quero dizer é que acredito que muitas das dificuldades profissionais atuais podem ser analisadas como decorrentes desse processo de profissionalização. Como se, atualmente, as instituições impedissem os profissionais de fazer seu trabalho, pelo menos aquele que gostariam de fazer e que encontram sentido e satisfação em realizar.

Vou dar um último exemplo. Atualmente, encontro, nos estabelecimentos escolares, educadores que foram formados tendo como base a psicologia, mas que nada conhecem de dinâmica de grupo. Não têm idéia do que possa ser uma instituição, mas têm grandes discursos e conceitos a apresentar sobre ela. Profissionais que se formaram com a idéia de uma invidualização da educação e que não sabem o que é trabalhar com um grupo de crianças. Os educadores mais antigos sabem trabalhar com grupo, mas não o fazem mais, pois essa prática tornouse desvalorizada. Como a autogestão, ela é considerada algo envelhecido. Eu não estou dizendo que a profissionalização é necessariamente algo negativo, digo que ela não é obrigatoriamente positiva, porque precisamos saber quais são as oportunidades que essa profissionalização vai oferecer, em particular devido a ser feita na universidade e ao desenvolvimento de dispositivos de análise de prática que para formam o que atualmente chamamos de práticos reflexivos. Acredito que os dispositivos e todos esses modos de formação podem se tornar tanto dispositivos de emancipação como de alienação.

A evolução da profissionalização vai permitir reconhecer a singularidade do indivíduo, mas pode também conduzir a uma terrível normalização. Essa questão é, atualmente, para nós franceses uma questão muito viva. Nesse momento, oriento uma estudante chinesa que me mostrou que nos textos oficiais do Ministério da Educação Chinês, igualmente são feitas análises de práticas e reflexões sobre a formação dos professores, dos educadores, etc. Ou seja, lá também a formação dos educadores se faz na universidade, e o discurso, igualmente, domi- 
na a prática. Entretanto, o marxismo-leninismo também faz parte das disciplinas ensinadas como uma obrigação ideológica. Suponho que essa reflexibilidade dos profissionais na China tem como limite o marxismo-leninismo.

\section{Notas}

${ }^{1}$ Produções da equipe de l'Axe socio-clinique institutionnelle de l'équipe ESSI da Universidade de Paris 8.

${ }^{2}$ Esse número corresponde ao número 7 de Les Cahiers de l'Implication. Revue d'analyse institutionnelle, nome anterior da publicação.

${ }^{3}$ Nota das tradutoras: Publicado no Brasil com o título de Análise Institucional (Lourau, 1975)

\section{REFERÊNCIAS}

DEVEREUX, G. De l'angoisse à la méthode dans les sciences du comportement. Paris: Flamarion, 1967.

L'HOMME ET LA SOCIETÉ. L'analyse institutionnelle: entre socio-clinique et socio-histoire. Paris: L'Harmattan, n. 147-148, 2003.

FAVRET-SAADA, J. Corps pour corps: enquête sur la sorcellerie dans le bocage. Paris : Gallimard, 1981.

LAMIHI, A.; MONCEAU, G. Instituition et Implication: l'oeuvre de René Lourau. Paris: Sylepse, 2002.

LOURAU, R. Análise Institucional. Rio de Janeiro: Vozes, 1975.

. Le journal de recherche: matériaux pour une théorie de l'implication. Paris: Méridiens-Klincksieck, 1988.

. Actes manqués de la recherche. Paris: PUF, 1994.

MONCEAU, G. Enquête sur les monographies d'interventions socianalytiques (1962-1999). Les Etudes Sociales, Paris, n. 133, p. 101-119, 2001.

- Transformar as práticas para conhecê-las: pesquisa-ação e profissionalização docente. Educação e Pesquisa, São Paulo, v. 31, n. 3, p. 467482, set./dez. 2005.

REVUE D'ANAYSE INSTITUTIONNELLE. Les Cahiers de l'Implication. Saint-Denis: L.S.E. - E.S.S.I, n. 1, 2006.

Recebido em: junho de 2007

Aceito em: novembro de 2007 